Journal of Clinical Investigation

Vol. 41, No. 4, 1962

\title{
PATHOGENESIS OF THE COAGULATION DEFECT DEVELOPING DURING PATHOLOGICAL PLASMA PROTEOLYTIC ("FIBRINOLYTIC") STATES. II. THE SIGNIFICANCE, MECHANISM AND CONSEQUENCES OF DEFECTIVE FIBRIN POLYMERIZATION *
}

\author{
BY NORMA ALKJAERSIG, ANTHONY P. FLETCHER AND SOL SHERRY \\ (From the Department of Medicine, Washington University School of Medicine, \\ St. Louis, Mo.)
}

(Submitted for publication July 13, 1961 ; accepted December 21, 1961)

A clinical syndrome characterized by a coagulation defect, hypofibrinogenemia, often an associated hemorrhagic diathesis and manifestations of whole blood or plasma "fibrinolysis" (spontaneous lysis of whole blood or plasma clots), has long been recognized. Usually developing acutely after the trauma of surgery or in association with certain obstetric complications, it may also present as a chronic syndrome complicating the course of long-term medical disease (reviews noted in References 1,2). Moreover, the iatrogenic induction of the syndrome, usually in a mild form, frequently accompanies the treatment of the acute thromboembolic complications of vascular disease by enzymatic means (3-6).

In an accompanying communication (1), it has been demonstrated that a coagulation defect developing during such pathological "fibrinolytic" states (states of abnormal plasma proteolytic activity) arises as a direct consequence of fibrinogen proteolysis. The defect is not the consequence of hypofibrinogenemia, for it may arise in patients with normal or near normal plasma fibrinogen values, but results from the presence of fibrinogen proteolysis products in plasma; these products interfere with normal coagulation mechanisms and produce the defect.

The essential laboratory features of the defect comprise hypofibrinogenemia (frequently mild), an increased thrombin clotting time, an increased

* This work was supported by a grant from the $\mathrm{Na}$ tional Heart Institute (H3745), United States Public Health Service, Bethesda, Md. Presented in part at the Fifty-first National Meeting of the American Society for Clinical Investigation, Atlantic City, N. J., May, 1959 ( J. clin. Invest. 1959, 38, 1005) and at the Thirty-third Annual Meeting of the Central Society for Clinical Research, Chicago, Ill., October, 1960 (J. Lab. clin. Med. $1960,56,813)$. one-stage "prothrombin" time, and associated abnormalities in clot formation.

The evidence presented in the accompanying report (1) indicated that: 1) the major features of the coagulation defect observed in vivo could be reproduced by adding fibrinogen proteolysis products to plasma in vitro; 2) the severity of the defect observed in vivo was well correlated with the observed extent of fibrinogen proteolysis and could be predicted by in vitro experiment, which would account quantitatively for the entire in vivo defect; 3 ) the severity of the in vivo defect was only poorly correlated with the actual plasma fibrinogen concentrations, and severe coagulation defects were observed even when plasma fibrinogen was in the normal or low normal range; and 4) the characteristics of the coagulation defect studied either in vivo or in vitro could be attributed to an interference by fibrinogen proteolysis products with the over-all coagulation step of fibrinogen-fibrin conversion.

Theoretically, fibrinogen proteolysis products might directly inhibit the enzymatic action of thrombin (conversion of fibrinogen to fibrin monomer), the subsequent spontaneous polymerization of fibrin monomer, or the gelation of fibrin polymer. Alternatively, the action of fibrinogen proteolysis products could inhibit more than one of these reactions. It will be the purpose of this communication to demonstrate that, although fibrinogen proteolysis products prolong the thrombin clotting time of plasma or purified fibrinogen solutions, the enzymatic actions of thrombin are not inhibited. Evidence also will be presented to show that the fibrinogen proteolysis products inhibit the polymerization of fibrin monomer and thus necessarily the gelation of polymer; structurally abnormal polymers, incorporating molecu- 
lar fragments of proteolysed fibrinogen, are formed, and this anomaly is responsible for aberrant clot formation. Moreover, purification studies indicate that the biochemically significant action of fibrinogen proteolysis products on coagulation resides in a single high molecular weight fibrinogen fragment, formed by plasmin action on fibrinogen, but resistant to further enzymatic digestion by plasmin.

This type of coagulation defect (i.e., the formation of abnormal polymers) has been termed defective fibrin polymerization; it may occur independently of or in conjunction with other coagulation defects. Possibly, defective fibrin polymerization may be involved in the pathogenesis of certain other clinical coagulation disorders, especially those observed in association with the dysproteinemias, which have hitherto lacked adequate explanation.

\section{MATERIALS AND METHODS}

\section{Preparations}

Single batches of bovine fibrinogen ${ }^{1}$ ( 99.2 per cent of the fibrinogen being clottable by thrombin) and human fibrinogen ${ }^{2}$ ( 92 per cent of the nitrogen being clottable by thrombin) were used throughout. Distinction between the species origin of fibrinogen used in various experiments has not been made in the text, since human and bovine fibrinogen yielded similar results in all experiments. Fibrinogen was iodinated with $\mathrm{I}^{181}$ by a previously described procedure (8).

Fibrinogen proteolysis products (labeled with $\mathrm{I}^{131}$ and unlabeled) were prepared by a previously described method (1). The heat-precipitable portion (15 minutes at $56^{\circ} \mathrm{C}$ ) of the $I^{131}$-labeled products was determined by centrifuging off the precipitate, washing once, and assaying precipitate supernatant and wash for isotopic activity.

Thrombin ${ }^{3}$ was a commercial preparation standardized in $\mathrm{NIH}$ units. Buffered saline refers to $0.1 \mathrm{M}$ phosphate with 0.9 per cent saline at $\mathrm{pH}$ 7.6. Dextran gel was of G 50 grade. 4 Soybean trypsin inhibitor ${ }^{5}$ (SBTI) was used at a concentration of $1 \mathrm{mg}$ per $\mathrm{ml}$.

\section{Methods}

Isotopic assays were made using a well-type scintillation counter and a pulse-height analyzer (1).

Ultrafiltration was performed using cellulosic membranes of graded porosity. ${ }^{6}$ Analytical ultracentrifugal

\footnotetext{
${ }^{1}$ Kindly supplied by Dr. Birger Blomback (7), Karolinska Institute, Stockholm, Sweden.

2 Kabi Company, Stockholm, Sweden.

${ }^{3}$ Parke, Davis Company, Detroit, Mich.

4 Pharmacia Co., Stockholm, Sweden.

5 Worthington Biochemical Corp., Freehold, N. J.

${ }^{6}$ Millipore Filter Corp., Bedford, Mass.
}

runs were made with a Spinco ${ }^{7}$ model $E$ at $52,640 \mathrm{rpm}$ using the double-sector cell, and at $59,780 \mathrm{rpm}$ using standard and wedge analytical cells. Preparative separation was performed using a Waugh-Yphantis ${ }^{7}$ cell. Fibrin clots for ultracentrifugal examination were prepared by clotting 1 to $2 \mathrm{ml}$ of a 1 to 3 per cent solution of purified fibrinogen, with or without added fibrinogen proteolysis products (concentration specified in text), with $0.1 \mathrm{ml}$ thrombin $(100 \mathrm{U}$ per $\mathrm{ml})$ at $37^{\circ} \mathrm{C}$. Two hours later the formed clots were placed in $1 \mathrm{~L}$ of buffered saline and washed for 24 to 72 hours at $2^{\circ} \mathrm{C}$ with stirring. Clots were then drained and completely dissolved in 30 per cent urea (by weight).

Thrombin clotting times were determined as previously described (3); buffer was omitted from the titration mixture when the determination was performed at other than $\mathrm{pH}$ 7.4. Fibrinogen assays were performed as previously described (1). The diagnosis of a coagulation disorder secondary to hyperplasminemia was established by previously described criteria (1).

Polymerization rates in plasma and in fibrinogen solutions, in the presence or absence of fibrinogen proteolysis products, were quantitated by a method modified from that of Ferry and Morrison (9). Serial absorbance readings at $3,500 \AA$ were made in a Beckman DU spectrophotometer ${ }^{7}$ at room temperature $\left(25^{\circ} \mathrm{C}\right)$. The clotting mixture contained $0.5 \mathrm{ml} \mathrm{SBTI}, 2 \mathrm{ml} 0.05 \mathrm{M}$ phosphate buffer at $\mathrm{pH} 6.0,0.5 \mathrm{ml}$ of plasma or fibrinogen solution, and $0.1 \mathrm{ml}$ thrombin ( $2 \mathrm{U}$ per $\mathrm{ml}$ ). Fibrinogen proteolysis products in $0.05 \mathrm{M}$ phosphate buffer at $\mathrm{pH} 6.0$ were substituted for plain buffer as required. The final reaction $\mathrm{pH}$ was 6.3. Thrombin esterase activity was assayed on $\mathrm{BAMe}^{8}$ using a previously described method (10).

The proteolytic action of thrombin on fibrinogen at $\mathrm{pH}$ 5.4 was studied by a method slightly modified from that of Ehrenpreis, Laskowski, Donnelly and Scheraga (11). The modifications were: fibrinogen concentration, $3 \mathrm{mg}$ per $\mathrm{ml}$; thrombin, $250 \mathrm{U}$ per $\mathrm{ml}$; and proteolysis products (when used) $3 \mathrm{mg}$ per $\mathrm{ml}$. BAMe to a final concentration of $0.04 \mathrm{M}$ was substituted for $\mathrm{TAMe}^{8}$ to inhibit thrombin action. (This substitution partly obviated the troublesome high blank value problem inherent in the original technique.) Fibrin monomer (f) and fibrinogen originally available (F) were determined by tyrosine assay on the isolated washed clot.

The proteolytic action of thrombin on fibrinogen at near neutral $\mathrm{pH}$ was studied by the method of Ehrenpreis and Scheraga (12). Reaction conditions were: $1.3 \mathrm{mg}$ fibrinogen and $1 \mathrm{U}$ thrombin in $5 \mathrm{ml} 0.1 \mathrm{M}$ phosphate buffer at $\mathrm{pH} 7.0$, with or without $1.3 \mathrm{mg}$ fibrinogen proteolysis products; the TAMe concentration of $0.04 \mathrm{M}$ gave a high blank value for control assays. In a further experiment, reaction conditions were modified: $1 \mathrm{mg}$ fibrinogen and $1 \mathrm{U}$ thrombin in $5 \mathrm{ml} 0.1 \mathrm{M}$ phosphate

\footnotetext{
${ }^{7}$ Beckman Spinco Corp., Palo Alto, Calif.

8 Benzoylarginine methyl ester (BAMe) and tosylarginine methyl ester (TAMe), Mann Laboratories, New York, N. Y.
} 
buffer at $\mathrm{pH} 7.6$, with or without $1 \mathrm{mg}$ fibrinogen proteolysis products; BAMe $0.03 \mathrm{M}$ final concentration was used to stop the reaction.

Assay for incorporation of $I^{131}$-labeled fibrinogen proteolysis products into clots. Aliquots $(0.2 \mathrm{ml})$ of fibrinogen-fibrinogen proteolysis product $\left(\mathrm{I}^{131}\right.$-labeled) mixtures were added to $0.7 \mathrm{ml}$ thrombin titration mixture and clotted with $0.1 \mathrm{ml}$ thrombin, $10 \mathrm{U}$ per $\mathrm{ml}$ (the thrombin titration mixture facilitated the complete recovery of fibrin). Thirty minutes later the clots were wound out on wooden applicator sticks, drained, and then washed for 10 minutes in $2 \mathrm{ml}$ Radiacwash. ${ }^{9}$ The drained clot, the original supernatant, and the wash were assayed for isotopic activity. Plasma-fibrinogen proteolysis product mixtures were treated similarly except that the aliquot volume was $0.5 \mathrm{ml}$, saline was substituted for the thrombin titration mixture, and clot formation took place over a 12-hour period.

\section{RESULTS}

The effect of fibrinogen proteolysis products on thrombin action. The thrombin clotting time of plasma (or purified fibrinogen solutions) is prolonged by the addition of fibrinogen proteolysis products, and this finding suggested that fibrinogen proteolysis products might inhibit either the enzymatic actions of thrombin or fibrin polymerization (1).

${ }^{9}$ A proprietary versene detergent solution; Atomlab Products, Center Moriches, Long Island, N. Y.
Figure 1 shows (left-hand portion) clotting times as a function of thrombin concentration in a plasma test system alone, and in the same test system when fibrinogen proteolysis products (2 $\mathrm{mg}$ per $\mathrm{ml}$ ) have been added. In both instances the thrombin clotting times shortened with increasing thrombin concentration, but at all thrombin concentrations the original difference between the thrombin clotting times of the two systems was preserved. The right-hand portion of the figure illustrates assays for thrombin esterase activity, using the synthetic substrate BAMe and employing the same thrombin concentrations used in the left-hand portion of the figure. The solid circles represent determinations with thrombin alone and the open circles, thrombin plus fibrinogen proteolysis products. The data from both sets of determinations fitted the same regression line and the results indicate that a concentration of fibrinogen proteolysis products sufficient to double the thrombin clotting time of the test system did not inhibit thrombin esterase activity.

Because of the high affinity of thrombin for $\mathrm{BAMe}$, these experiments were repeated using fibrinogen rather than BAMe as the substrate. Figure 2 illustrates assay of thrombin proteolytic activity, measured on fibrinogen, in the presence and absence of fibrinogen proteolysis products at

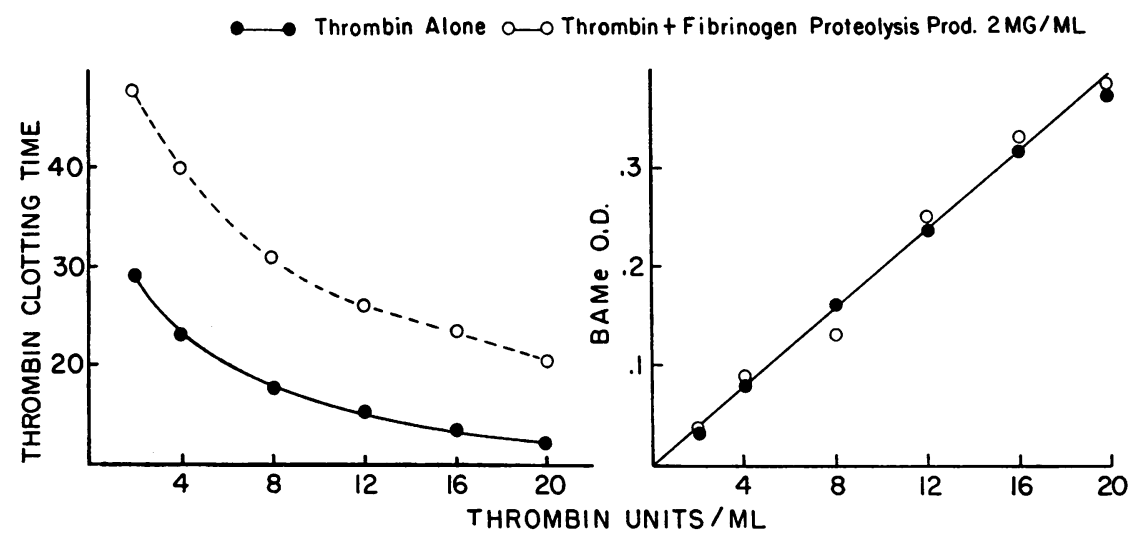

Fig. 1. (Left) Thrombin clotting times (ordinate) as a function of thromBIN CONCENTRATION (ABSCISSA) FOR A NORMAL PLASMA AND FOR THE SAME PLASMA CONTAINING FIBRINOGEN PROTEOLYSIS PRODUCTS (2 Mg PER ML). (RIght) BAME ESTERASE ACTIVITY (ORDINATE) AS A FUNCTION OF THROMBIN CONCENTRATION (ABSCISSA) IN THE PRESENCE AND IN THE ABSENCE OF FIBRINOGEN PROTEOLYSIS PRODUCTS (2 MG PER ML). Despite the striking increase in thrombin clotting time that results from the presence in plasma of fibrinogen proteolysis products (left-hand panel), the enzymatic actions of thrombin on BAMe were not inhibited by these products (righthand panel). 


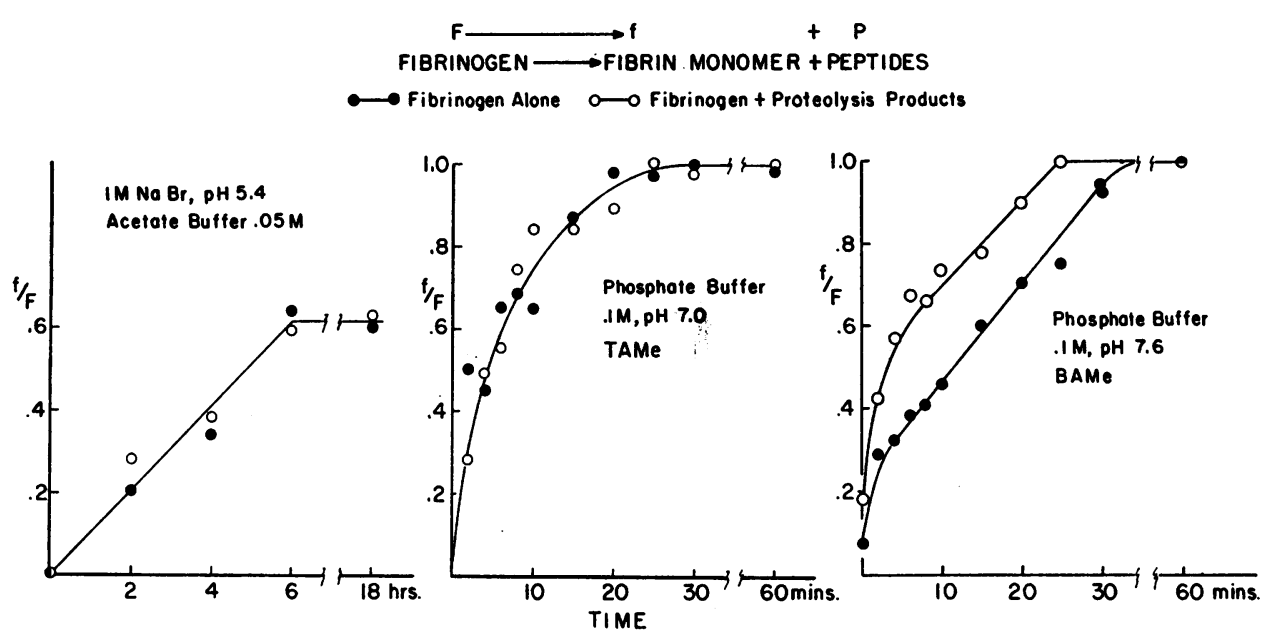

Fig. 2. Enzymatic action of thrombin MEASUREd on Fibrinogen AND DETERMined in the PRESENCE AND ABSENCE OF FIBRINOGEN PROTEOLYSIS PRODUCTS. The ordinate $f / F$ is the ratio of fibrin monomer formed by thrombin action (f) and total potential monomer ( $F$ ). On the left, the abscissa is time in hours, but in the other two panels it is in minutes. Three series of reaction conditions are illustrated (see Methods) : on the left the reaction $\mathrm{pH}$ was 5.4 , in the middle 7.0, and on the right 7.6. Equal proportions of fibrinogen and fibrinogen proteolysis products were used, but in none of the experiments did fibrinogen proteolysis products inhibit the enzymatic actions of thrombin on fibrinogen.

$\mathrm{pH}$ 5.4, 7.0, and 7.6. Techniques designed to measure only fibrinogen-fibrin monomer conversion (see Methods) were employed, a requirement imposing technical restrictions on the assay conditions. In the left-hand panel, reaction conditions were $\mathrm{pH} 5.4$ and $1 \mathrm{M}$ sodium bromide concentration; these conditions permitted monomer formation, but prevented polymer or gel formation. BAMe was used as a thrombin inhibitor. In the middle and right-hand panels, polymer formation from monomer could not be prevented because of the $\mathrm{pH}$ employed, but the reactions were stopped using TAMe and BAMe as thrombin inhibitors. In all three panels the ordinate $f / F$ is the ratio between $f$, the amount of monomer formed during the experiment (estimated by inhibiting thrombin action and recovering the monomer in polymer form), and $F$, the fibrinogen originally available in the assay system; the abscissa is reaction time. At near neutral $\mathrm{pH}$, very low thrombin concentrations $(0.2 \mathrm{U}$ per $\mathrm{ml}$ ) were mandatory, and the assays were not as reproducible as those made at $\mathrm{pH}$ 5.4. In all three panels of Figure 2, the solid circles represent assays made using the thrombin-fibrinogen system alone and the open circles the same system with the addition of fibrinogen proteolysis prod- ucts (the same relative concentration employed in Figure 1).

The left and middle panels indicate that at $\mathrm{pH} 5.4$ and $\mathrm{pH} 7.0$, even though the ratio of fibrinogen proteolysis products/fibrinogen corresponded to a coagulation defect of considerable severity (see Figure 1), monomer production from fibrinogen by thrombin was unimpaired in the presence of fibrinogen proteolysis products. Although the data in the right-hand panel of Figure 2 suggest that thrombin action may have been slightly potentiated by the presence of fibrinogen proteolysis products, this appearance is artifactual due to precipitation of a portion of the proteolysis products by BAMe. The insignificance of the apparent difference is shown by the fact that the reaction slopes are identical, whereas potentiation of thrombin action would have produced divergent slopes. Because of the low thrombin concentrations employed, this small displacement between the reaction slopes would be, in any case, of negligible importance.

The effect of fibrinogen proteolysis products on the polymerization step. The data displayed in Figures 1 and 2 demonstrated that, although the addition of fibrinogen proteolysis products to fibrinogen or plasma prolonged the thrombin 
clotting time of the solution, the enzymatic actions of thrombin itself were unaltered. These findings suggested that the action of fibrinogen proteolysis products was to inhibit the polymerization or gelation of fibrin monomer, or both, and validated the approach illustrated in Figure 3, in which spectrophotometric methods were used to study polymerization rates. As shown by Ferry and Morrison (9), the rate of absorbance increase, measured at 3,500 $\AA$ during the coagulation of fibrinogen, is an indirect measure of light scattering and consequently a measure of polymerization rates.
The left-hand portion of Figure 3 shows serial absorbance readings (ordinate) made on diluted plasma to which has been added successive increments of fibrinogen proteolysis products. The abscissa is time in minutes, and thrombin was added at zero minutes. Inhibition of fibrin polymerization, its magnitude dependent on the concentration of added fibrinogen proteolysis products, is clearly demonstrated. At 12 hours (not illustrated) the absorbance of all solutions was found to be approximately similar. The righthand portion of Figure 3 illustrates similar determinations on a normal plasma, on plasma from

\section{TURBIDITY MEASUREMENTS}

\section{BUFFER PH 6.3, $\mu$ 0.1, THROMBIN 0.05 U/ML.}

Normal Plosma + Vorying Amounts of

Patients with Coagulation Defect

\section{Fibrinogen Digest}

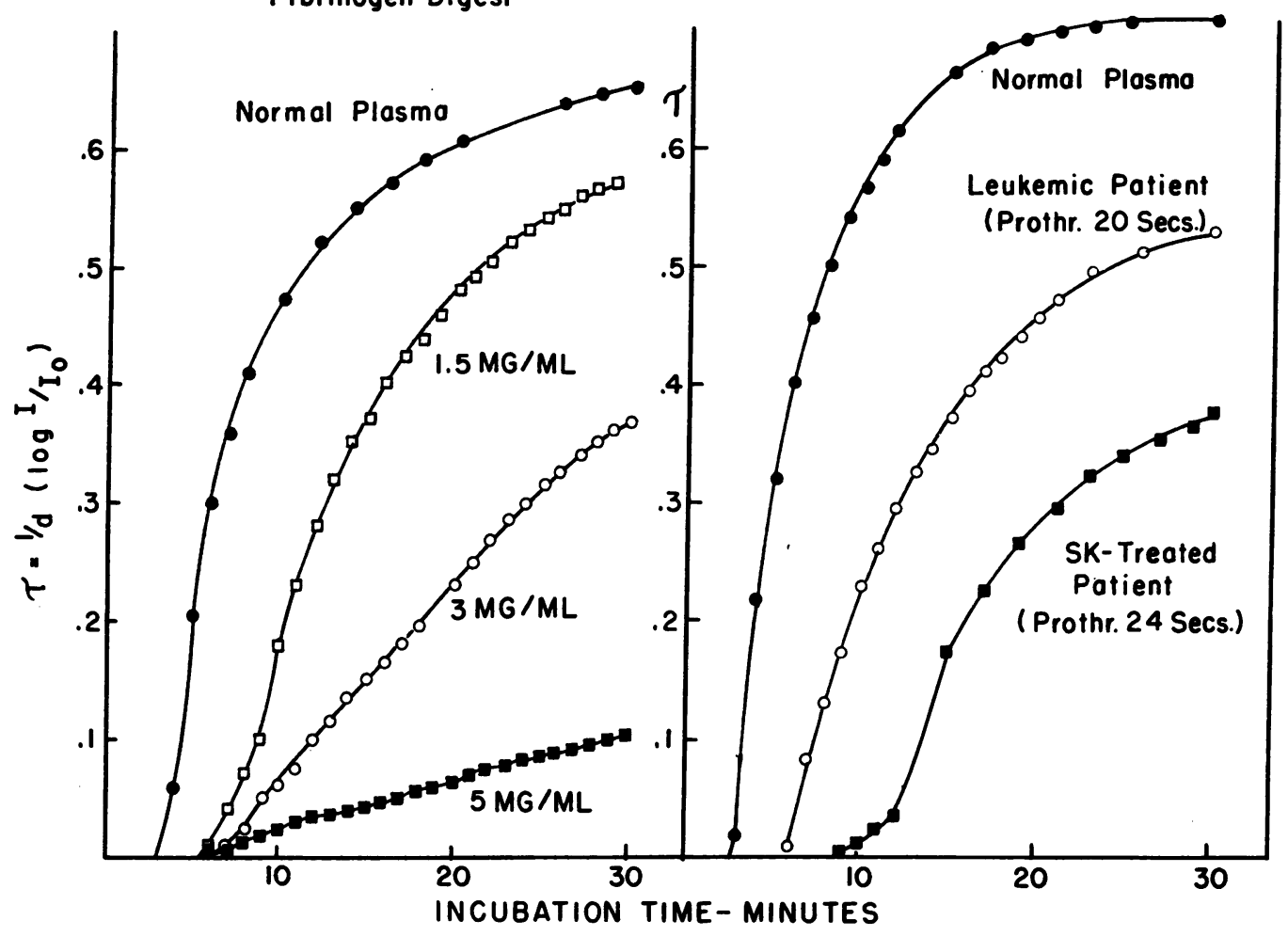

Fig. 3. Serial absorbance readings at 3,500 ^ (ordinate) made on various plasmas treated With THROMBIN AT ZERo TIME (ABSCISSA, TIME IN MINUTES). The left-hand panel displays results with normal plasma and with aliquots containing fibrinogen proteolysis products (3 concentrations). Inhibition of polymerization was roughly proportional to the concentration of fibrinogen proteolysis products. On the right are shown results with a normal plasma, plasma from a leukemic patient who developed an abnormal plasma proteolytic state with a coagulation defect, and plasma from a SKtreated patient exhibiting a coagulation defect. Inhibitory curves in both panels exhibit marked similarity. 


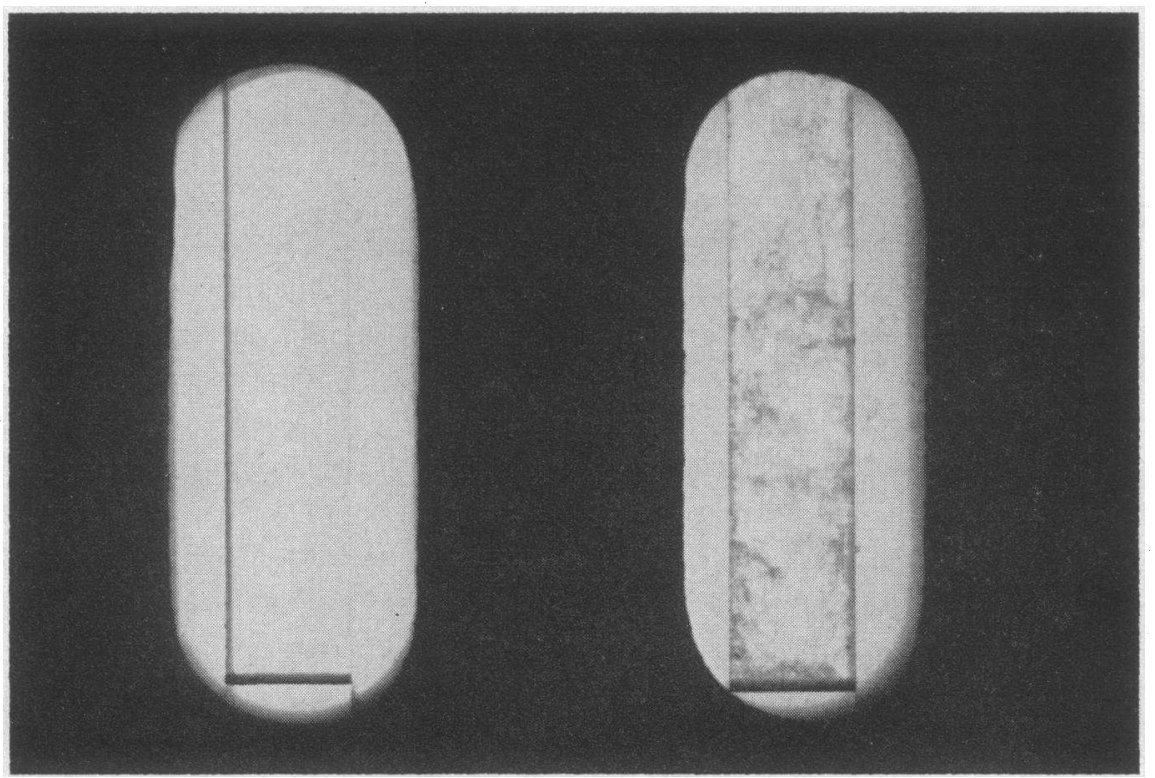

FIG. 4. CLOTS FORMED IN 1-CM CUVETS ON THE LEFT FROM PURIFIED FIBRIN MONOMER (0.65 MG PER ML) AND ON THE RIGHT UNDER THE SAME CONDITIONS EXCEPT THAT FIBRINOGEN PROTEOLYSIS PRODUCTS (1 MG PER ML) HAD BEEN ADDED PRIOR TO CLOTTING. The macroscopic abnormality in clot formation occurring in the presence of fibrinogen proteolysis products is clearly visualized. (Photographic reproduction has somewhat exaggerated the differences observed visually.)

a patient suffering from acute granulocytic leukemia, and on plasma from a patient receiving streptokinase (SK) therapy; these latter two patients demonstrated evidence of excessive plasma proteolysis (1). Substantial inhibition of fibrin polymerization rates was demonstrated in both abnormal plasma samples.

The macroscopic changes in clot structure resulting from inhibition of fibrin polymerization by fibrinogen proteolysis products are illustrated in Figure 4. To insure that inhibition of fibrin polymerization was the only mechanism responsible for the difference in clot appearance, the clots were prepared from fibrin monomer stored in $1 \mathrm{M}$ bromide at $\mathrm{pH} 5.3$ (11). The use of thrombin was not required, since fibrin monomer stored in this fashion polymerizes spontaneously on dilution and with alteration of $\mathrm{pH}$. The lefthand control monomer clot was formed from 0.1 $\mathrm{ml}$ fibrin monomer $(8.0 \mathrm{mg}$ per $\mathrm{ml}$ in $1 \mathrm{M}$ bromide at $\mathrm{pH} 5.3$ ) and $1.1 \mathrm{ml} 0.1 \mathrm{M}$ phosphate buffer at $\mathrm{pH} 6.5$; the right-hand clot was formed similarly except that $0.1 \mathrm{ml}$ fibrinogen proteolysis products (13.0 mg per $\mathrm{ml}$ ) was substituted for an equal volume of buffer. Both clots are viewed by transmitted light and the characteristic disturbance to clot structure is well visualized. Although Figure 4 illustrates an extreme variation from the normal, it is often possible, when performing a fibrinogen assay on the plasma of a patient suffering from a pathological proteolytic state, to make a presumptive diagnosis on the basis of gross aberrations in clot appearance.

Properties of the polymerization inhibitor and its isolation from fibrinogen proteolysis products. An ultracentrifugal pattern illustrative of the general characteristics exhibited by crude fibrinogen digests is shown in Figure 5 (a plasmin digest of fibrinogen). The direction of migration is from left to right and the pattern shows the fastest moving component ( $5 \mathrm{~S}$ class) as a well defined peak. The slower moving components are not resolved in this pattern, but will be shown later to be comprised of two main molecular classes with sedimentation constants centered around 1.4 and 3 . However, these lowest molecular weight components exhibited differences in various preparations according to the method of digest preparation. 
Figure 6 displays observations made during the proteolysis of bovine fibrinogen $(3.6 \mathrm{mg}$ per $\mathrm{ml}$ ) by plasmin $(2.7$ casein units per $\mathrm{ml})$ at $37^{\circ} \mathrm{C}$. Polymerization inhibitor was assayed by its effect on prolonging the thrombin clotting time of the test solution, and the results are expressed in seconds (left-hand ordinate). TCA ${ }^{10}$-soluble tyrosine was expressed as per cent of total tyrosine (right-hand ordinate), and the abscissa is time of incubation in minutes.

The titer of polymerization inhibitor rapidly increased during the first few minutes of digestion; at 25 minutes, by which time it had become stable, a sample aliquot was withdrawn for ultracentrifugal examination (arrow on diagram). No further alteration in polymerization inhibitor titer occurred during the remainder of the experiment, although the TCA-soluble tyrosine increased slowly from 14 per cent at 25 minutes to 17 per cent at 180 minutes. A second sample for ultracentrifugal examination (arrow on dia-

${ }^{10}$ Trichloroacetic acid.

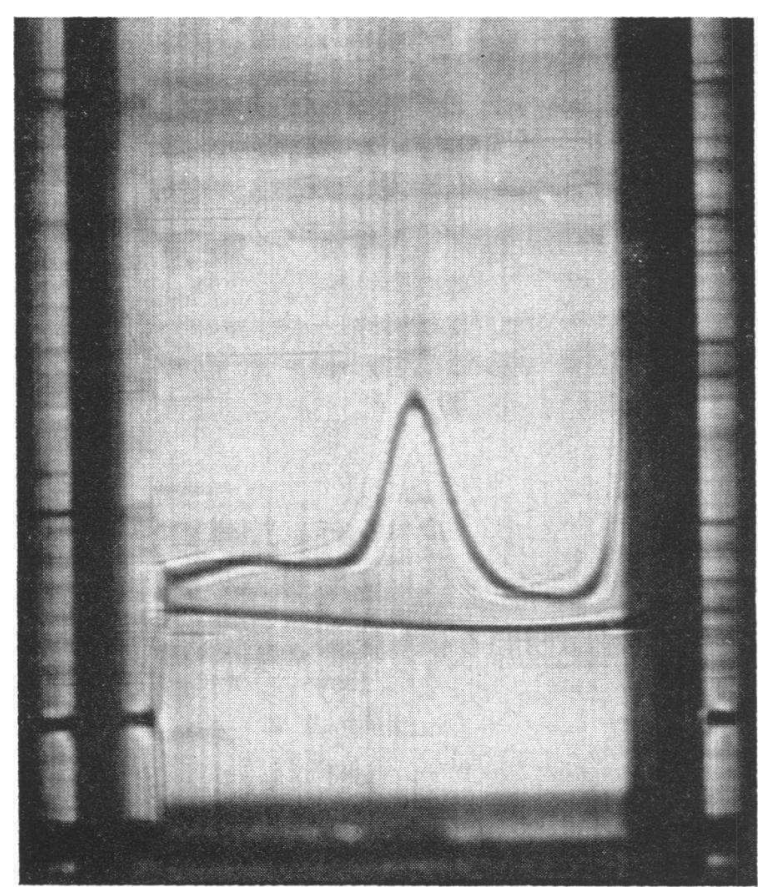

Fig. 5. Ultracentrifugal Pattern of a Plasmin DIGEST OF FIBRINOGEN (DIRECTION OF MIGRATION FROM LEFT TO RIGHT). The fastest moving component (5S class) presents as a single well defined peak; the slower moving components are not resolved in the pattern, but exhibit wide nonhomogeneity. Planimetry shows the $5 \mathrm{~S}$ peak to be in a $1: 1$ ratio with the other components.

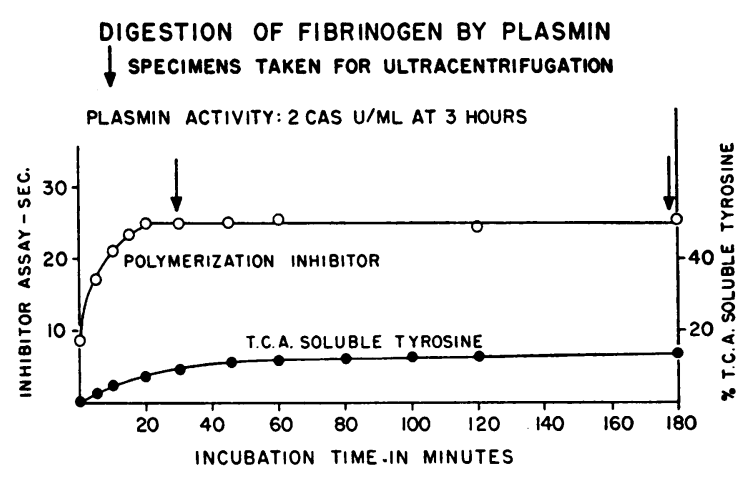

Fig. 6. Proteolysis of Fibrinogen (3.6 Mg PER ML) BY PLASMIN (2.7 U PER ML). Inhibitor assay (seconds) is plotted on the left-hand and TCA-soluble tyrosine (per cent) on the right-hand ordinate; the abscissa is time in minutes. Inhibitor titer increased rapidly and reached a plateau in 20 minutes, but TCA-soluble tyrosine increased slowly throughout the 180-minute incubation period. Arrows mark the time of sample removal for ultracentrifugation (Figure 7).

gram) was withdrawn at 180 minutes and the solution assayed for plasmin activity; a considerable residual excess of plasmin ( 2 casein units per $\mathrm{ml}$ ) was demonstrated. These observations indicate that the polymerization inhibitor produced from fibrinogen during proteolysis by plas$\mathrm{min}$ is stable against further enzymatic digestion by plasmin.

Figure 7 displays the two ultracentrifugal patterns from the Figure 6 experiment; the upper pattern (the 25-minute specimen) was run in a prismatic cell and the lower pattern (the 180minute specimen) in a standard cell during the same rotor run. The fastest moving component observed in each pattern had exactly the same mobility during the run $\left(\mathrm{s}_{20, \mathrm{w}} 4.9\right)$, and by planimetry after rerun in double-sector cells the two component areas were determined to be of equal size ( 49 per cent of the total pattern area). Identical results were obtained when fibrinogen of human origin was substituted for fibrinogen of bovine origin in these experiments.

Ultrafiltration studies suggested that the polymerization inhibitor was a substance of relatively high molecular weight. Aliquots of a tryptic fibrinogen digest, giving a thrombin clotting time of 55 seconds in the assay system and containing $1.3 \mathrm{mg}$ tyrosine per $\mathrm{ml}$, were filtered through 50 $\mathrm{m} \mu$ and $100-\mathrm{m} \mu$ cellulosic ultrafiltration membranes at $\mathrm{pH} \mathrm{7.0.} \mathrm{The} 50 \mathrm{~m} \mu$ filtrate contained 


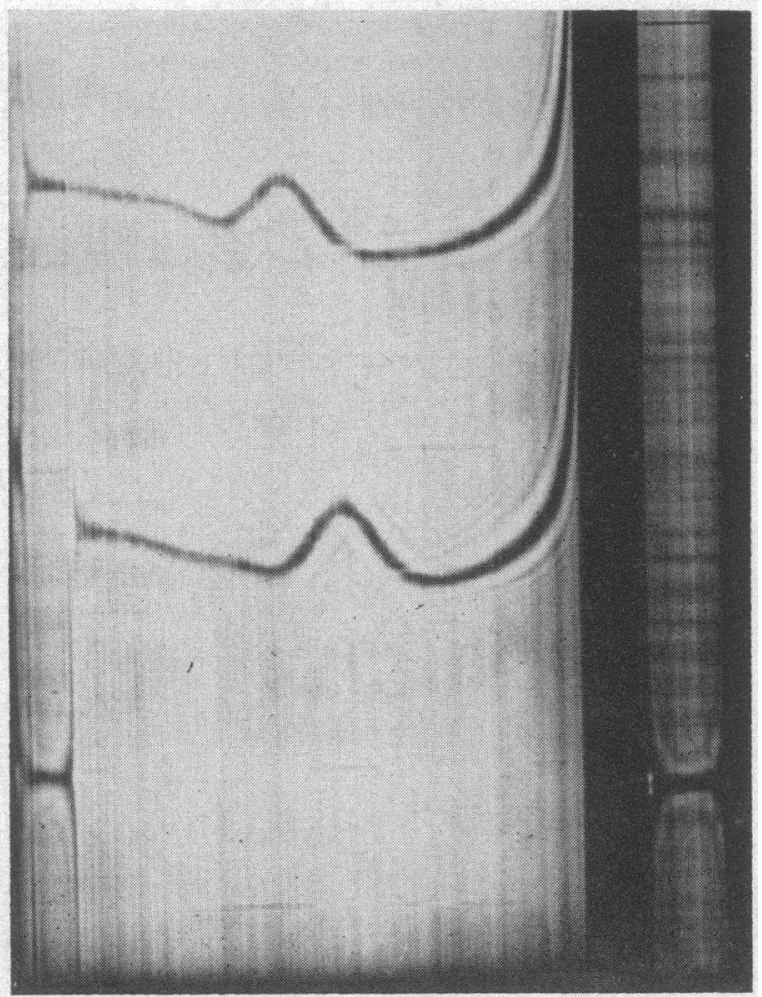

Fig. 7. Samples From the eXPeriment SHOWN in FiguRE 6 SUBJECTED to ULTRACENTRIFUgation DURING THE SAME ROTOR RUN (MIGRATION FROM LEFT TO RIGHT). The upper pattern is the 25-minute and the lower the 180-minute sample from Figure 6 . The fastest running components in the two patterns exhibited identical ultracentrifugal sedimentation constants, and by planimetry their areas were equal.

$0.102 \mathrm{mg}$ tyrosine per $\mathrm{ml}$ and gave a thrombin time of 14.7 seconds in the assay system, while the $100 \mathrm{~m} \mu$ filtrate contained $1.02 \mathrm{mg}$ tyrosine per $\mathrm{ml}$ and gave a thrombin clotting time of $40 \mathrm{sec}-$ onds.

Figure 8 illustrates an ultracentrifugal fractionation performed with the aid of a YphantisWaugh separation cell on a plasmin digest of fibrinogen. The figure is a reproduction of a doubly exposed plate, the first exposure being made just prior to braking the centrifuge, and the second after the partition had closed during deceleration. An excellent separation between the slow and fast running components was accomplished. Assays on the two samples showed the slow-running fraction to contain $0.64 \mathrm{mg}$ tyrosine per $\mathrm{ml}$ and this gave a thrombin clotting time of 35 seconds in the assay system, while the fast-running fraction contained $1.74 \mathrm{mg}$ tyrosine per $\mathrm{ml}$ and gave a thrombin clotting time of 127 seconds in the assay system. The original plasmin digest contained $1.29 \mathrm{mg}$ tyrosine per $\mathrm{ml}$ and gave a thrombin clotting time of 69 seconds. The results of this and two similar experiments suggested (bearing in mind that contamination between the two sections of the ultracentrifugal separation cell is often difficult to prevent) that the inhibitory activity to fibrin monomer polymerization resided largely or perhaps solely in the large fast-running component of the digest pattern, and that the components with lower molecular weight did not inhibit polymerization.

Selective heat precipitation offered an alternative approach to the characterization of the component(s) in the fibrinogen proteolysis products responsible for inhibiting fibrin polymerization. Proteolysis of $\mathrm{I}^{131}$-labeled fibrinogen was produced by plasmin digestion, and an aliquot was removed for ultracentrifugal examination. The solution was then heated at $56^{\circ} \mathrm{C}$ for 15 minutes and the precipitate which formed was removed

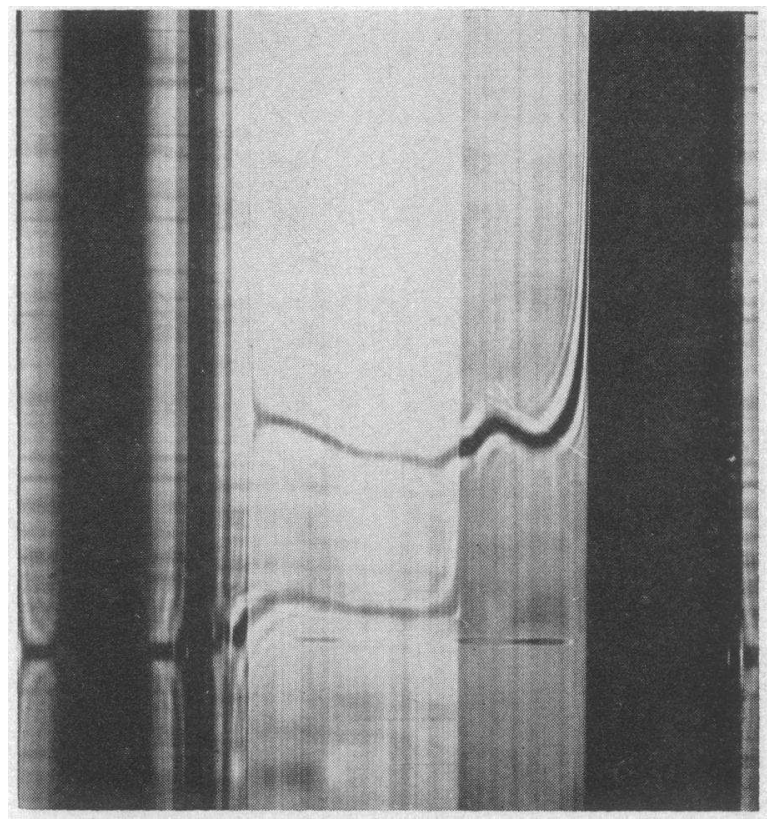

Fig. 8. Fractionation OF FIBRINOGEN PROTEOLysis PRODUCTS IN A YPHANTIS-WAUgh SEPARATION CELL (MIGRATION FROM LEFT TO RIGHT). The upper tracing is the pattern at the time of rotor deceleration; by means of a second exposure after the partition had closed, the excellent separation obtained between fast and slow moving components is demonstrated (dark band over the right half of the pattern). 
by centrifugation and washed once before assay for $\mathrm{I}^{131}$.

Figure 9 displays ultracentrifugal patterns on both the original solution and on the heat-treated supernatant; the lower pattern is that of the original digest (diluted 1:2, standard cell) and the upper that of the supernatant (undiluted, prismatic cell) during the same rotor run. The lower pattern shows three components with approximate sedimentation constants of $1.4,3$, and 5 , and by planimetry, after superimposition against the appropriate baseline, the respective component areas were 29.7, 20.7, and 49.6 per cent of the total pattern area. The upper tracing shows only two components with sedimentation constants of 1.4 and 3 ; the pattern areas, 58.5 and 41.5 per cent, bear a similar ratio (29.7 $: 20.7$ ) to the 1.4 and $3 \mathrm{~S}$ components measured in the lower tracing. The $5 \mathrm{~S}$ component, occupying 49.6 per cent of the original pattern area,

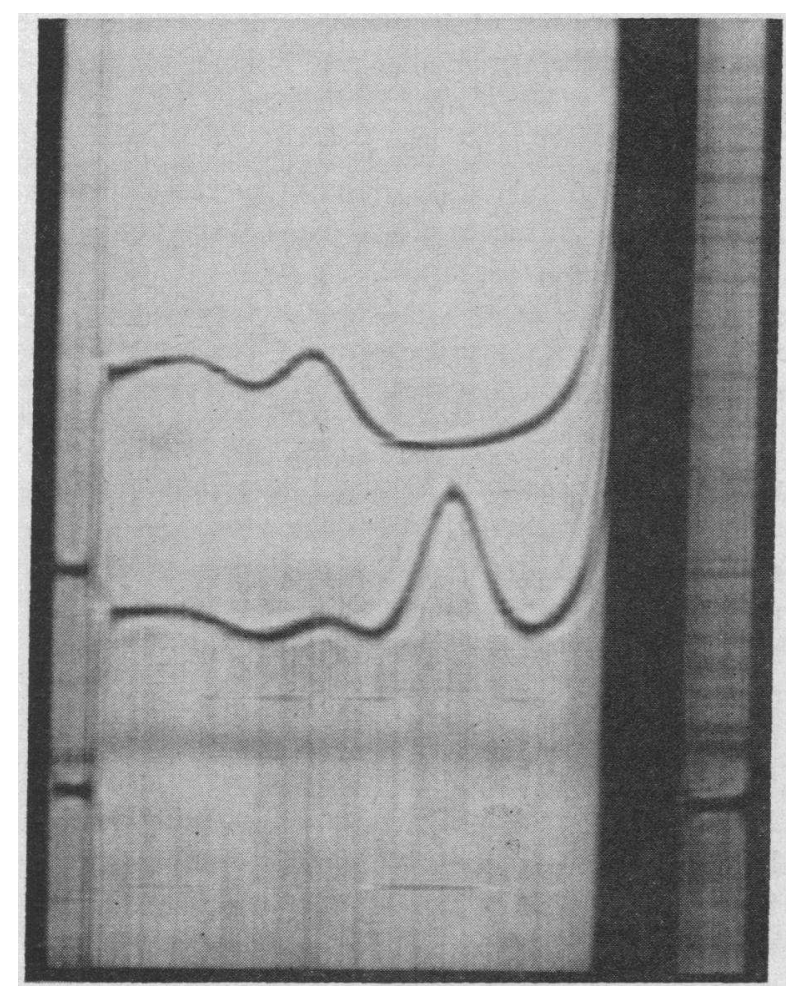

Fig. 9. EFFECT OF HEAT ON FIBRINOGEN PROTEOLYSIS PRODUCTs. The top ultracentrifugal pattern is from an aliquot heated at $56^{\circ} \mathrm{C}$ for 15 minutes with precipitated protein removed. The bottom pattern is the unheated aliquot (diluted $1: 2$ ). Heating has caused complete precipitation of the $5 \mathrm{~S}$ fragment, but of no other (see text).

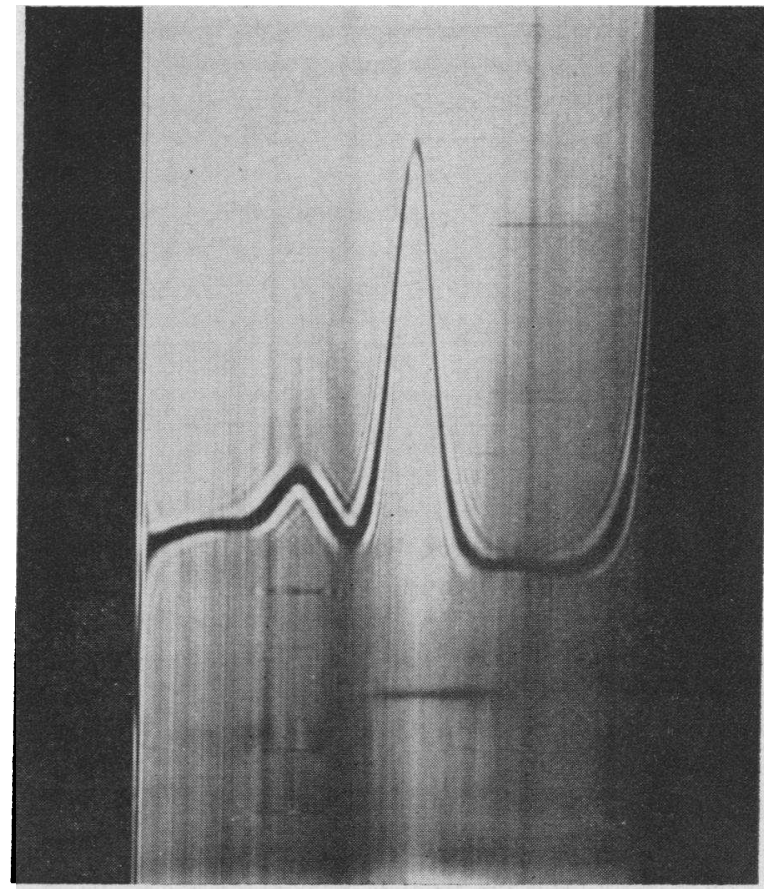

Fig. 10. Ultracentrifugal pattern (Migration FROM LEFT TO RIGHT) OF THE PARTIALLY PURIFIED POLYMERIZATION INHIBITOR AFTER FRACTIONATION OF FIBRINOGEN PROTEOLYSIS PRODUCTS ON DEXTRAN GEL (G 50 GRADE). The main peak, the $5.27 \mathrm{~s}_{20}$, w fragment (see Figure 11) appears to be homogenous, but contamination with $3 \mathrm{~S}$ material is still present.

was absent from the supernatant pattern. This component had been precipitated by the heating process, and assay for $\mathrm{I}^{131}$ in the precipitate showed that 48 per cent of the original $\mathrm{I}^{131}$ activity was present, as compared to the 49.6 per cent loss calculated by planimetry. This observation indicated that the extent of $\mathrm{I}^{131}$-labelling between the $5 \mathrm{~S}$ fragment and the other fibrinogen fragments was similar. Other experiments involving fractionation of fibrinogen digests, by ultracentrifugation, ultrafiltration, dextran gel filtration, and differential chemical precipitation, confirmed this finding.

The original solution ( $1: 5$ dilution) prolonged the thrombin clotting time of the assay system from 12 to 33 seconds, while the heated supernatant (1:5 dilution) only prolonged it from 12 to 15 seconds. These observations were consistent with the hypothesis that precipitation of the 5S component by heat had removed the polymerization inhibitor, although the possibility that heat 


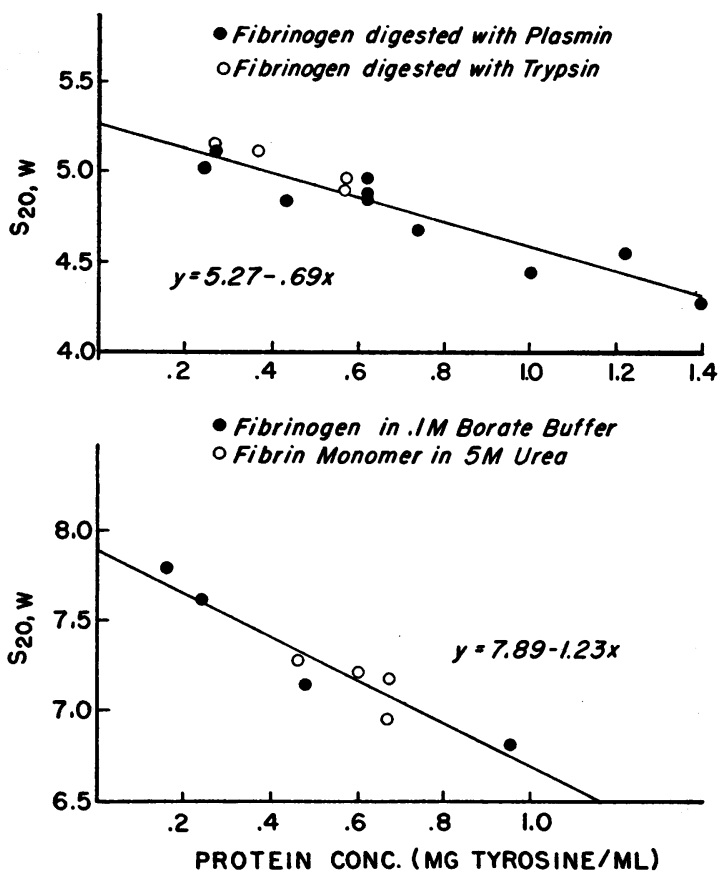

Fig. 11. S20, w AS A FUNCTION OF PROTEIN CONCENTRATION FOR FIBRINOGEN, FIBRIN MONOMER, AND FIBRINOGEN DIGESTED WITH TRYPSIN AND PLASMA. The upper graph displays ultracentrifugal mobility data as a function of protein concentration for the large molecular weight enzyme-stable fragment formed from fibrinogen by plasmin or trypsin action: the fragment formed by either enzyme exhibited identical sedimentation characteristics, the $\mathbf{s}_{20,}, \mathrm{w}$ extrapolated to zero concentration being 5.27. The lower graph shows similar data for fibrinogen run in $0.1 \mathrm{M}$ borate buffer and for fibrin monomer in $5 \mathrm{M}$ urea; the identity between the two confirms the validity of the corrections applied for use of this medium.

had denatured the polymerization inhibitor could not be excluded. The relative electrophoretic mobilities of the heat-precipitable fibrinogen proteolysis product and purified fibrinogen were studied by zone electrophoresis using cellulose acetate strips. Simultaneous electrophoretic runs were performed using purified fibrinogen, fibrinogen digest, and heat-treated fibrinogen digest at $\mathrm{pH}$ 's between 7 and 9 . The results indicated that within methodological limitations fibrinogen and the heat-precipitable fibrinogen proteolysis product possessed similar electrophoretic mobilities.

Two $\mathrm{ml}$ of fibrinogen proteolysis products (plasmin digest) was fractionated by dextran gel chromatography (G 50 grade). The column void volume was $22 \mathrm{ml}$, and the ultracentrifugal pattern shown in Figure 10 was run on the 22- to 25-ml specimen. Good separation of the 5S fragment was obtained, although the ultracentrifugal pattern demonstrated contamination with the $3 \mathrm{~S}$ component. Assay of both the original solution and this column fraction demonstrated that more than 80 per cent of the original polymerization inhibitor activity was present in the column fraction. Evidently, the whole or at least the major portion of the polymerization inhibitory activity resided in the $5 \mathrm{~S}$ fragment, although participation of the $3 \mathrm{~S}$ fragment in this reaction could not be excluded.

Figure 11 displays ultracentrifugal sedimentation data as a function of protein concentration for the 5S fragment, fibrin monomer, and fibrinogen. The upper section of the figure demonstrates that the sedimentation characteristics of the 5S component, whether formed from fibrinogen by plasmin or trypsin action, were similar; the $s_{20, w}$ for this component, extrapolated to zero protein concentration, was in both instances 5.27. The lower section of Figure 11 cites sedimentation data on fibrin monomer and fibrinogen; these gave an $\mathrm{s}_{20, \mathrm{w}}$ value of 7.89 for both materials. This finding validates the corrections applied to the crude sedimentation values in cases (vide infra) where ultracentrifugal runs were made in 30 per cent urea $(5 \mathrm{M})$.

Pathogenesis of defective fibrin polymerization. Theoretically, inhibition of fibrin polymerization by fibrinogen proteolysis products could arise in either of two ways. First, the forces of intermolecular attraction between monomer units could be diminished through the presence of fibrinogen proteolysis products, resulting in purely physicochemical inhibition of polymerization; or second, fibrin monomer could combine with the proteolysis products and the latter complex, perhaps lacking a sufficiency of suitable linkage sites, fail to unite with other monomer or polymer units. In the first case polymerization would be inhibited but a structurally normal clot would be formed, while in the second, not only would polymerization be inhibited, but a structurally abnormal clot would result. Resolution of this problem was undertaken by an analysis of clots formed in the presence and in the absence of fibrinogen proteolysis products.

Figure 12 shows ultracentrifugal patterns on two clots dissolved in urea. One clot was formed 
from purified fibrinogen and thrombin, and the other from a similar mixture to which fibrinogen proteolysis products had been added. After thorough washing ( 48 hours at $2^{\circ} \mathrm{C}$ ), the clots were dissolved in urea and examined in double sector ultracentrifugal cells (the greatly curved base lines reflect the presence of urea). Whereas the clot formed from purified fibrinogen showed only one component, fibrin monomer (Figure 12A), the clot formed in the presence of fibrinogen proteolysis products (Figure 12B) revealed the inclusion of substantial quantities of other components. Since the clots had been washed thoroughly, this finding suggested the incorporation of fibrinogen proteolysis products into the clot structure. Moreover, pattern planimetry revealed that the $5.27 \mathrm{~s}_{20, w}$ fragment had been preferentially taken up into the clot structure; the ratio of this component to the other proteolysis products was $2: 1$ in the clot pattern, whereas in the crude digest patterns (Figures 5, 7,9) the ratio was $1: 1$.

Quantitation of this phenomenon was undertaken using I I31-labeled fibrinogen proteolysis products. In these studies, the small physical size

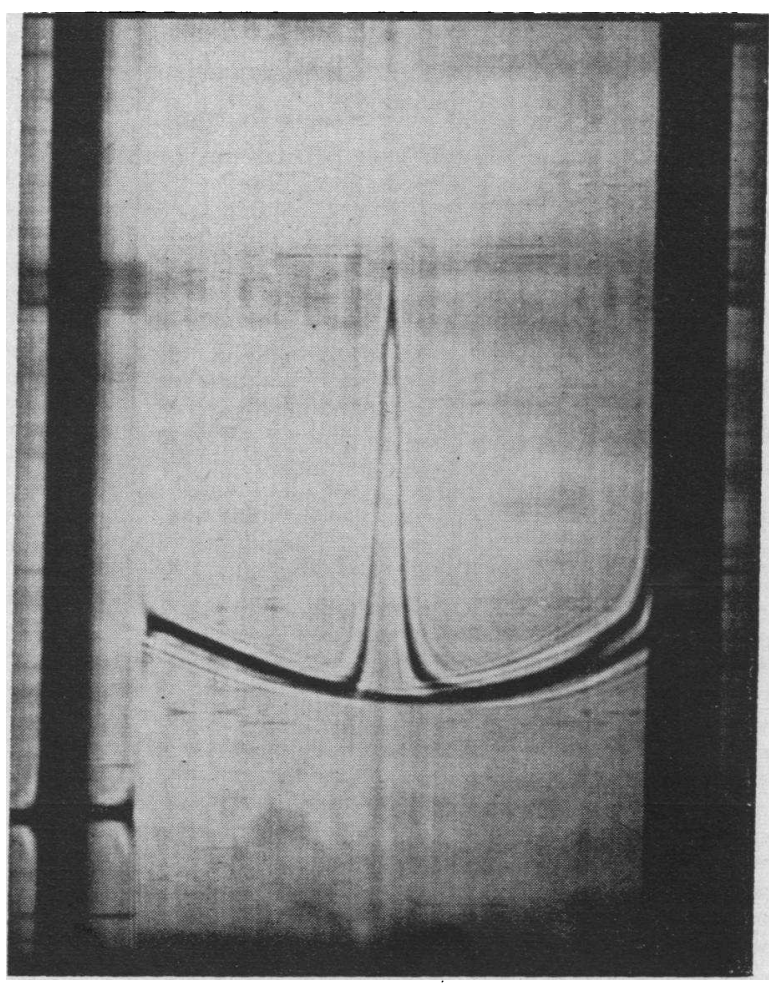

A

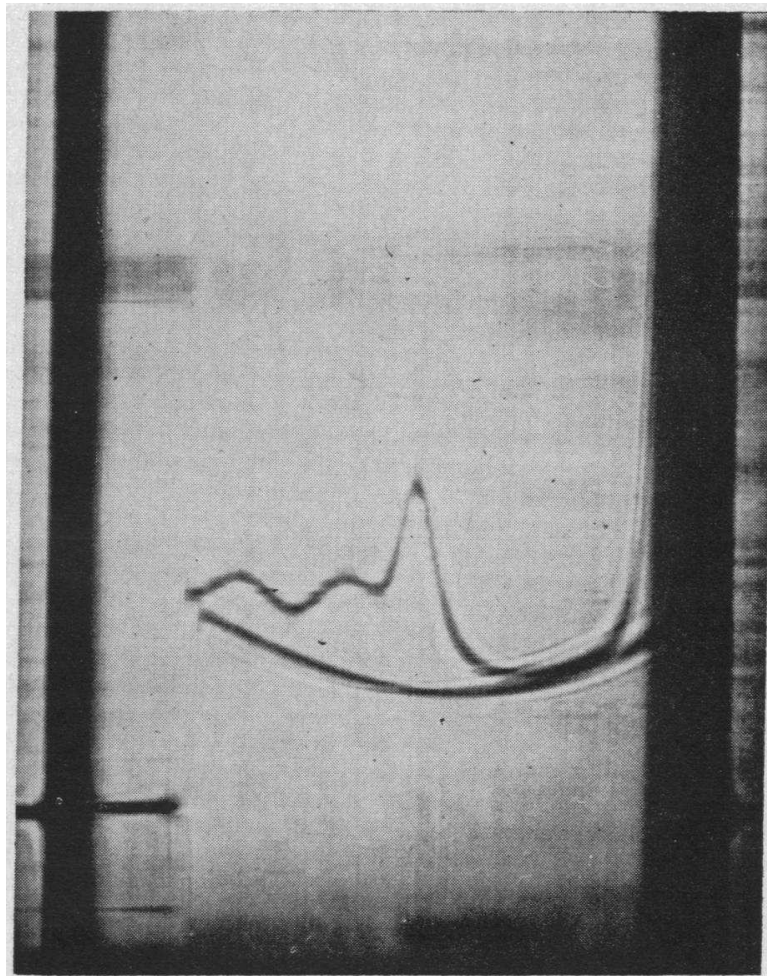

B

Fig. 12. A. Ultracentrifugal pattern of a Clot disSOLVED IN 5 M UREA, FORMED FROM PURIFIED FIBRINOGEN AND THROMBIN, WASHED AND SOLUBILIZED. Fibrin monomer is the only component present. B. A SIMILAR STUDY EXCEPT THAT THE ORIGINAL SOLUTION HAD CONTAINED FIBRINOGEN PROTEOLYSIS PRODUCTS. Three components are present, from right to left : fibrin monomer, the $5.27 \mathrm{~s}_{20, w}$ fibrinogen fragment, and fibrinogen proteolysis products of lower molecular weight, chiefly $3 \mathrm{~S}$. The $5.27 \mathrm{~s}_{20, w}$ fragment has been preferentially incorporated into the clot, since the ratio of this fragment to the others is $2: 1$ (determined by planimetry), whereas in the original digest it was $1: 1$.

of the clots facilitated the removal of contaminating protein not incorporated into the clot structure. Figure 13 displays the results of studies involving the degree of proteolysis product incorporation with varying $\mathrm{pH}$. The top section of the diagram illustrates the variation in thrombin clotting time observed when native plasma and plasma containing fibrinogen proteolysis products were tested between $\mathrm{pH} 6.5$ and $\mathrm{pH} 9.0$. Both the normal and the abnormal plasmas showed similar prolongation of the thrombin clotting times at extremes of the tested $\mathrm{pH}$ range, and the curves for thrombin clotting time against 

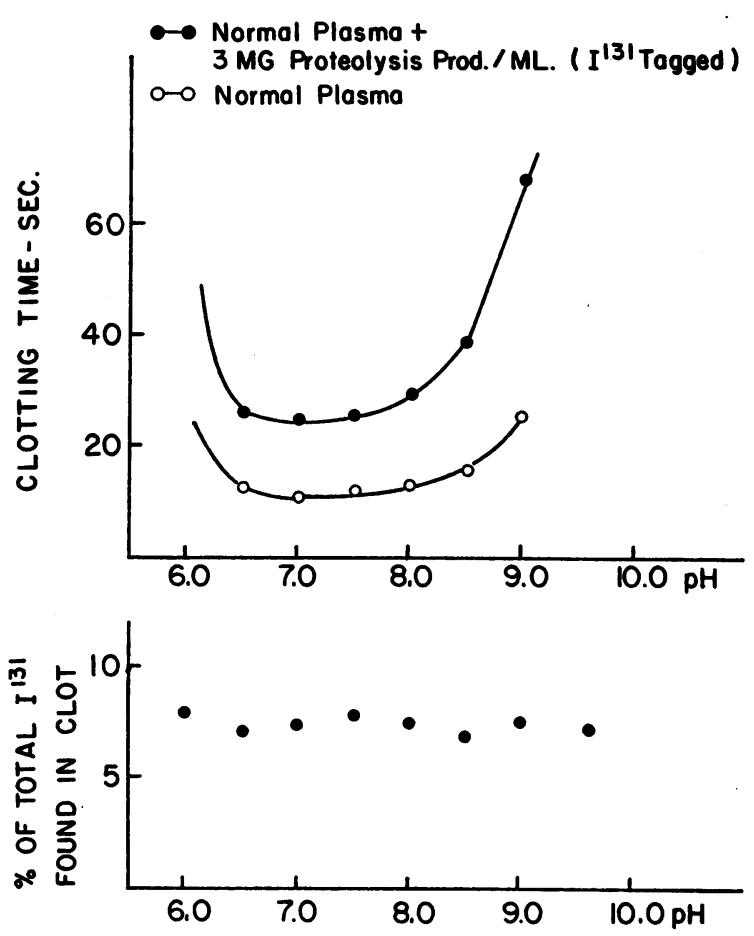

Fig. 13. Clot formation as a function of pH. The top section displays thrombin clotting times (ordinate) as a function of $\mathrm{pH}$ (abscissa) for normal plasma and for plasma containing fibrinogen proteolysis products $(3 \mathrm{mg}$ per $\mathrm{ml}, \mathrm{I}^{131}$-labeled). The two curves, although separated from each other throughout their course, are similarly influenced by change of reaction $\mathrm{pH}$. The lower section, isotopic content of clots (ordinate) and reaction $\mathrm{pH}$ (abscissa), displays analyses on clots formed from the mixtures examined in the top section. The quantity of fibrinogen proteolysis products (estimated as $\mathrm{I}^{131}$ ) present in the clots was independent of reaction $\mathrm{pH}$.

reaction $\mathrm{pH}$ approximately paralleled each other. However, despite the variation in thrombin clotting time observed with altered $\mathrm{pH}-\mathrm{a}$ finding attributed to the effects of $\mathrm{pH}$ both on thrombin action and on polymer formation (9) - the lower section of the diagram demonstrates that the percentage incorporation of I $^{131}$-labeled fibrinogen proteolysis products was constant (limits, 7 to 8 per cent) at different $\mathrm{pH}$ reaction values.

To provide information as to the class of fibrinogen proteolysis products $(1.4 \mathrm{~S}, 3 \mathrm{~S}$, or $5 \mathrm{~S}$ components) incorporated into the clot, advantage was taken of the experimental findings displayed in Figure 9 (namely, that the 5S component of fibrinogen digests was precipitated selectively by heating at $56^{\circ} \mathrm{C}$ for 15 minutes). The experiment cited in Table I was conducted in a manner similar to that described in Figure 13, except that after the clot had been removed and assayed for radioaetivity the supernatant was heated at $56^{\circ}$ $\mathrm{C}$ for 15 minutes. The resulting precipitate was centrifuged off and assayed for radioactivity (column 2, Table I), and the residual supernatant radioactivity was also determined (column 3, Table I). The difference in radioactivity between the findings recorded in columns 2 and 3 for the solutions which had been clotted and for the unclotted control solution permitted calculation of the percentage of heat-precipitable fibrinogen proteolysis products removed with each clot. This calculation (column 4, Table I) indicates that, in the different experiments, between 82 and 100 per cent of the $\mathrm{I}^{131}$ assayed in the clots was heat precipitable and consequently in the form of $5 \mathrm{~S}$ fibrinogen proteolysis product, the particular component previously implicated as responsible for inhibition of fibrin monomer polymerization.

Further data pertaining to the extent of fibrinogen proteolysis product incorporation into clots are presented in Figure 14. Fibrinogen concentration varied from 0.5 to $5 \mathrm{mg}$ per $\mathrm{ml}$, but the concentration of fibrinogen proteolysis products ( $\mathrm{I}^{131}$-labeled) was held constant $(1.5 \mathrm{mg}$ per $\mathrm{ml})$. Since the thrombin concentration (10 U per $\mathrm{ml}$ ) was also held constant, the difference in thrombin clotting times between the control and the solutions containing proteolysis product measured the severity of the coagulation defect produced by

TABLE I

Properties and type of fibrinogen proteolysis products incorporated into plasma clots

\begin{tabular}{|c|c|c|c|c|}
\hline & $\begin{array}{c}\mathrm{I}^{131} \text { in } \\
\text { clot }\end{array}$ & $\begin{array}{c}\text { I131 } \\
\text { (from } \\
\text { supnt.) } \\
\text { in heat } \\
\text { ppte }\end{array}$ & $\begin{array}{l}\text { Is1 in } \\
\text { residual } \\
\text { supnt. } \\
\text { after } \\
\text { clotting } \\
\text { and } \\
\text { heating }\end{array}$ & $\begin{array}{l}\text { Clot } \\
\text { Il11 in } \\
\text { heat- } \\
\text { precip- } \\
\text { itable } \\
\text { form } \\
\text { (calcu- } \\
\text { lated) }\end{array}$ \\
\hline & $\%$ & $\%$ & $\%$ & $\%$ \\
\hline Proteolysis product & No clot & 48 & 52 & \\
\hline $\begin{array}{r}\text { Plasma pH : } 6.0 \\
6.5 \\
7.0 \\
7.5 \\
8.0 \\
8.5\end{array}$ & $\begin{array}{l}7.8 \\
7.8 \\
7.1 \\
7.8 \\
7.5 \\
7.5\end{array}$ & $\begin{array}{l}39.2 \\
41.4 \\
37.4 \\
40.6 \\
41.4 \\
41.0\end{array}$ & $\begin{array}{l}53 \\
50.5 \\
55.1 \\
51.6 \\
51.0 \\
51.3\end{array}$ & $\begin{array}{r}100 \\
82 \\
100 \\
87 \\
93 \\
92\end{array}$ \\
\hline
\end{tabular}

* Experimental conditions as in Figure 13. The first three columns are $I^{131}$ determinations expressed as a percentage of total radioactivity. The last column is the calculated proportion of I131-labeled fibrinogen proteolysis products expressed as a percentage of the total proteolysis products incorported into the clots. The results indicate that at plasma pH values between 6.0 and 8.5 (ung pr the experimental conditions described) 82 to $100 \%$ of the incorporated fibrinogen proteolysis (see Figure 8). 
alteration of the ratio of proteolysis products/fibrinogen. The top section of Figure 14 displays thrombin clotting times plotted against the reciprocal of fibrinogen concentration for solutions either lacking or containing fibrinogen proteolysis products. For both sets of determinations, a linear relationship exists between the variables, although each set is divergent from the other. Indeed this double reciprocal plot, analagous to a Lineweaver-Burk plot, suggested that the polymerization of fibrin monomer was competitively inhibited in the presence of fibrinogen proteolysis products (vide supra).

The extent of fibrinogen proteolysis product incorporation in these clots is illustrated in the lower portion of Figure 14. The ordinate plots

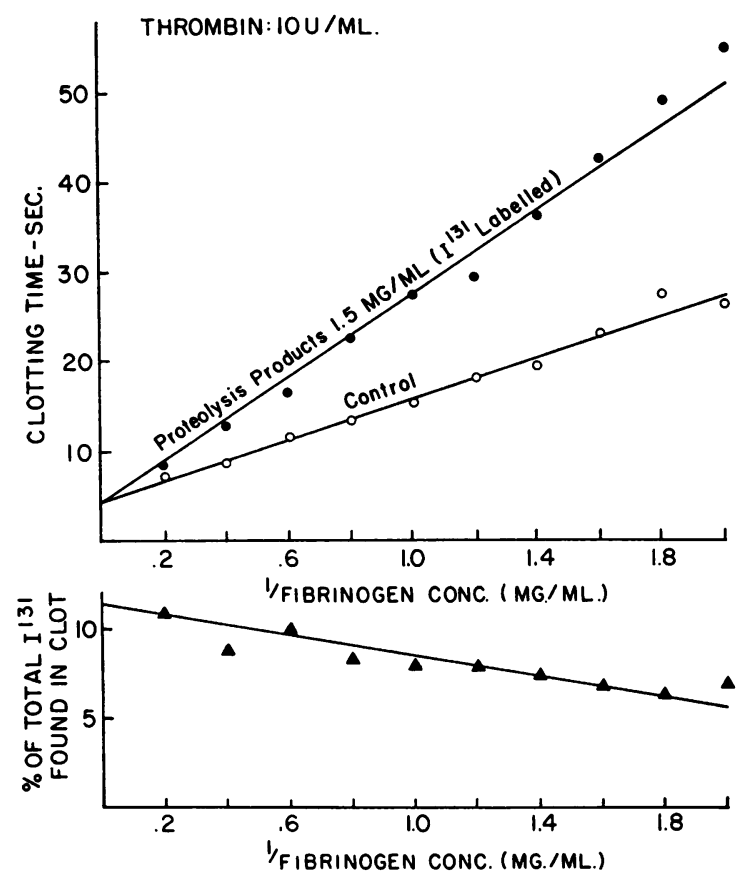

Fig. 14. Competitive inhibition of Clotting BY PRoTEOLYSIS PRODCCTS. The top section shows the influence of fibrinogen concentration ( $1 /$ fibrinogen concentration, abscissa) on clotting time (ordinate) for a control fibrinogen solution and identical aliquots containing $\mathrm{I}^{131}$-labeled fibrinogen proteolysis products ( $1.5 \mathrm{mg}$ per $\mathrm{ml}$ ). A single thrombin concentration was used and the results suggest a competitive inhibition of fibrin polymerization by the proteolysis products. The lower section (abscissa identical with the top section; ordinate per cent of total $\mathrm{I}^{131}$ found in the clots) demonstrates that clot composition, with respect to the incorporation of $\mathrm{I}^{131}$-labeled fibrinogen proteolysis products, was related reciprocally rather than linearly to the original fibrinogen concentration.

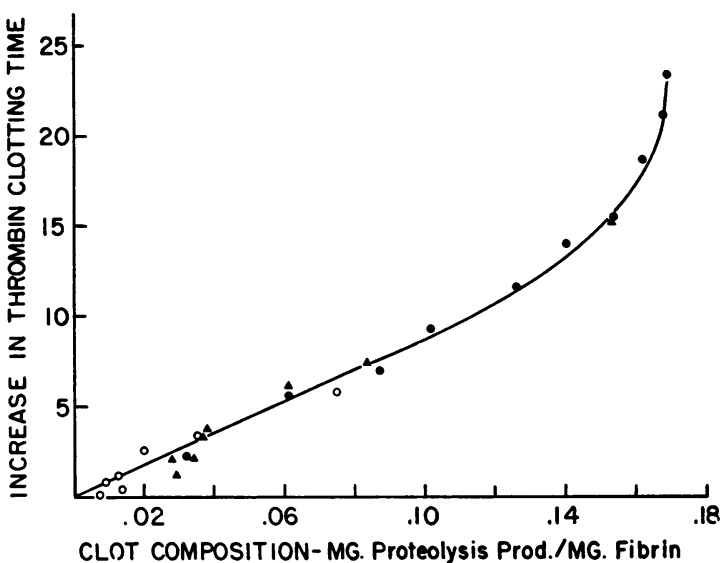

Fig. 15. Relation between severity of coagulation DEFECT AND CLOT COMPOSITION. The degree of coagulation anomaly, produced by adding varying concentrations of fibrinogen proteolysis products ( $\mathrm{I}^{131}$-labeled) to fibrinogen, is quantitated as increase of thrombin clotting time on the ordinate. Washed clots formed from these fibrinogen solutions were analyzed for radioactivity and tyrosine content, and the findings shown on the abscissa in terms of clot composition ( $\mathrm{mg}$ proteolysis products per $\mathrm{mg}$ fibrin). A linear relationship existed between the degree of coagulation anomaly and clot composition expressed in this manner.

the percentage of the original $\mathrm{I}^{131}$-labeled fibrinogen proteolysis products contained in the clot; the abscissa is the reciprocal of the original fibrinogen concentration. A linear relationship between these variables is apparent, more $\mathrm{I}^{131}$ labeled proteolysis products being contained in clots formed from solutions with higher fibrinogen concentrations. Nevertheless, even under these conditions, utilizing a single concentration of fibrinogen proteolysis products, a tenfold variation in fibrinogen concentration resulted in only a twofold change in clot radioactivity.

Figure 15 displays data from Figure 14 analyzed, together with that of two other experiments of similar design, to determine whether the severity of the coagulation defect influenced clot composition. In the two other experiments, fixed fibrinogen concentrations ( 5 and $2.1 \mathrm{mg}$ per $\mathrm{ml}$, respectively) were employed, but the concentration of fibrinogen proteolysis products $\left(\mathrm{I}^{131}\right.$ labeled) was varied. Increase of thrombin clotting time (the difference between the two sets of assays, top section of Figure 14 and similar differences for the other experiments) was plotted against the ratio of fibrinogen proteolysis prod- 
ucts/fibrin determined by clot analysis. As shown in Figure 15, a linear relationship between severity of the coagulation defect (increase of thrombin clotting time on ordinate) and clot composition (ratio fibrinogen proteolysis products/fibrin) existed. However, when the percentage of proteolysis products in the clot rose above 12 per cent, increasing severity of the coagulation defect was not reflected by a proportionate change in clot composition.

These results suggest that the mechanism by which fibrinogen proteolysis products inhibit fibrin polymerization involves the formation of abnormal polymers composed of fibrin monomer units and the $5.27 \mathrm{~s}_{20, w}$ fibrinogen proteolysis fragment. These abnormal polymers, probably lacking a sufficiency of binding sites, then inhibit polymerization and result in the formation of a structurally abnormal clot. Such a hypothesis also would explain the ultimate deviation from linearity shown in Figure 15.

\section{DISCUSSION}

Coagulation studies, especially clinical coagulation studies, have hitherto suffered from an extraordinary restriction of the available experimental approach, as has been stressed by Biggs and Macfarlane (13). Fibrin formation, involving the full complexity of fibrinogen-fibrin conversion, has necessarily had to serve as the prime measure and sole indicator of each of a long series of interrelated reactions; yet recent evidence $(14,15)$ has demonstrated that fibrinogenfibrin conversion is itself a complex of multiphasic reactions, each of which is susceptible to influence by altered reaction conditions. The present evidence demonstrates that such altered reaction conditions arising clinically (1) may themselves inhibit fibrinogen-fibrin conversion in a striking fashion. Consequently, if "specific coagulation factor assays" are made using such plasmas, erroneous results may be obtained unless precautions to obviate this difficulty are observed.

The present findings concerning the physicochemical nature of fibrinogen proteolysis products formed by plasmin action are in close agreement with those recently reported by Nussenzweig, Seligmann, Pelmont and Grabar (16-18), whose admirable studies of the antigenic determinants contained in fibrinogen included physicochemical characterization of proteolysis products resulting from plasmin action on fibrinogen. Their component $D$, which carries one of the fibrinogen antigenic markers, is clearly identical with the fibrin polymerization inhibitor with a sedimentation constant of $5.27 \mathrm{~s}_{20, \mathrm{w}}$ described in this communication. In fact, if allowance is made for the relatively limited centrifugal data in their paper, which hinder extrapolation of their calculated $\mathrm{s}_{20, \mathrm{w}}$ values to zero concentration, agreement on the sedimentation findings can be regarded as complete. These investigators determined the diffusion constant on their large molecular weight fragment to be $5.3 \times 10^{-7} \mathrm{~cm}^{2} \mathrm{sec}^{-1}$, which permitted them to calculate a molecular weight of 83,000 for this fragment. Moreover, the properties of the $5.27 \mathrm{~S}$ fibrinogen fragment with respect to all the characteristics studied-heat precipitability, relative electrophoretic mobility compared to fibrinogen, relative abundance in the fibrinogen digest, and chemical behavior-appeared to be identical with the $\alpha$-fibrinogen derivative described by Seegers, Nieft and Vandenbelt (19). Of particular relevance to the present investigation was their finding that the $\alpha$-fibrinogen derivative, studied over an extensive range of $\mathrm{pH}$ by free boundary electrophoresis, exhibited a mobility identical with that of fibrinogen. Consequently, it may be inferred that the $5.27 \mathrm{~S}$ fibrinogen fragment and fibrin monomer (20) probably differ significantly, but not widely, in net charge.

The biophysical data pertaining to fibrinogen proteolysis products formed by trypsin action are subject to some uncertainty in interpretation: although our data suggested that the fragments formed by plasmin and trypsin action were identical, none of our fibrinogen batches was plasminogen-free. Consequently, since trypsin is a plasminogen activator, the possibility exists that our "trypsin" digests may have been subjected to both plasmin and trypsin action.

Indeed in some experiments with other fibrinogen batches there have been indications that the large molecular weight fibrinogen fragment produced by tryptic digestion may exhibit a somewhat higher sedimentation constant than the $5.27 \mathrm{~s}_{20, w}$ determined for the fragment formed by plasmin digestion. However, both large molec- 
ular weight fibrinogen fragments (formed respectively by plasmin and trypsin action) appear to inhibit fibrin polymerization in a quantitatively identical manner.

The preliminary data of Mihalyi and Godfrey ${ }^{11}$ are in general agreement with our findings concerning the properties of fibrinogen proteolysis products formed by trypsin digestion. They determined an $s_{20, w}$ of 5.6 and calculated a molecular weight of 102,000 for the large fragment. However, their fibrinogen batches presumably were not plasminogen-free, and consequently their sedimentation data may be subjected to the same artifactual influence as our own.

The evidence implicating the large molecular weight fibrinogen fragment $\left(5.27 \mathrm{~s}_{20, \mathrm{w}}\right)$ formed by plasmin action as the component responsible for the polymerization defect is strong. This fragment when isolated, although not in a state of complete purity by ultracentrifugal, ultrafiltration, or gel filtration procedures, alone possessed inhibitory activity in the assay system. Moreover, both heat-stability studies on fibrinogen digests and the data displayed in Table I, which indicated that the moiety of fibrinogen proteolysis products incorporated into clots was predominantly of the $5.27 \mathrm{~S}$ variety, confirmed this hypothesis. Nevertheless, the data do not exclude the possibility that the $3 \mathrm{~S}$ fragment may exert a minor role as an inhibitor of polymerization, since the 5.27S fibrinogen fragment was contaminated with the $3 \mathrm{~S}$ fragment.

Our findings indicate that fibrinogen proteolysis products inhibit and alter the character of the polymerization reaction so that a structurally abnormal clot is formed. This abnormality of structure results from the incorporation of a specific fibrinogen proteolysis fragment (5.27S) within the clot structure, and the degree of such structural abnormality (determined by clot analysis with respect to the $5.27 \mathrm{~S}$ fibrinogen fragment) correlates well with the degree of polymerization defect (Figure 15).

Although consideration must be given to the possibility that these latter results could have been influenced by nonspecific absorption of fibrinogen proteolysis products onto or into the fibrin gel network, the evidence would suggest

\footnotetext{
${ }^{11}$ Fed. Proc. 1961, 20, 385.
}

either that this did not occur or that it was relatively unimportant. First, the method of clot recovery involved thin film syneresis, draining, and washing-all procedures that have been shown to reduce clot contamination by extraneous protein to a very low figure (21). Second, the incorporated fibrinogen proteolysis product, determined by clot analysis, was shown to consist primarily of only one class of fibrinogen fragment (the $5.27 \mathrm{~S}$ fragment implicated in the pathogenesis of the polymerization defect) rather than the several present in the original digest. Finally, as discussed above, the quantity of $5.27 \mathrm{~S}$ fibrinogen proteolysis product recovered from the clot, while well correlated with the degree of polymerization defect was but poorly correlated with the original fibrinogen concentration (Figure 14). Moreover, the inferential evidence (as apart from the direct) implicating the polymerization-gelation stage of fibrinogen-fibrin conversion as the site of the biochemical lesion in this coagulation defect is of an overwhelming character; for in sensitive assay systems, employing the substrates $\mathrm{BAMe}$ and fibrinogen, we have demonstrated that fibrinogen proteolysis products do not interfere with the enzymatic actions of thrombin. Thus the experimental data pertaining to the incorporation of the 5.27S fibrinogen fragment into clots are a logical extension of the other findings.

The concept that fibrinogen proteolysis products interfere with fibrinogen-fibrin conversion at the polymerization-gelation stage of the reaction, and only at this stage, is contrary to the original interpretations of two other groups (22-27). These investigators inferred that, since fibrinogen proteolysis products when added to plasma or fibrinogen solutions increased the thrombin clotting time of the mixtures, thrombin action was inhibited. One group (22) suggested that these proteolysis products should, on the grounds of their presumed action, be designated "Antithrombin VI." However, recently $(28,29)$ both groups interpret newer findings to indicate that both polymerization and thrombin action may be inhibited. In these circumstances the suggested designation for fibrinogen proteolysis products, Antithrombin VI, would clearly be unsatisfactory. If further work confirms the concepts advanced in this communication, and in the event that a descriptive term is needed, nomenclature 
such as "Polymerization Inhibitor I" would be appropriate.

Our evidence regarding inhibition of polymerization rates by fibrinogen proteolysis products during the early stages of this reaction is necessarily imperfect. The modified light-scattering procedure used for quantitation of polymerization rates is a method which, although exceedingly useful for the study of this complex reaction; yields a relative rather than an absolute measure of rate. Although inhibition of polymerization was roughly proportional to the concentration of added fibrinogen proteolysis products, it is clear that, since only relative rates were determined, calculation of kinetic data would be invalid. Nevertheless these data, in conjunction with those cited earlier, suffice to establish that all phases of polymerization, both early and late, are inhibited by the presence of fibrinogen proteolysis products.

Support for these concepts has been provided by investigations involving study of polymerization rates of purified fibrin monomer in the presence and in the absence of fibrinogen proteolysis products $(30,31)$. In this assay system, in which polymerization rates are dependent solely on physicochemical reaction conditions, we have demonstrated, in line with the present findings, that polymerization rates involving both early and late phases of the reaction are progressively inhibited over a wide range of reaction conditions by fibrinogen proteolysis products. Moreover, in an accompanying manuscript (32), electron microscopic studies of clots formed from both purified fibrinogen solutions and plasma containing either crude fibrinogen digests or purified $5.27 \mathrm{~S}$ fragments have permitted visualization of the presumed abnormal polymer. These studies have confirmed our present hypothesis concerning disordered clot structure.

The mechanism by which defective fibrin polymerization produces such obvious macroscopic changes in clot structure as are illustrated in Figure 4 is conjectural. As discussed earlier, although net charge differences probably exist between the 5.27S fibrinogen fragment and fibrin monomer, these net charge differences are unlikely to be of significant magnitude although it is possible that the net charge of the polymers themselves may differ more widely than that of their components. Nevertheless it is tempting to specu- late that the abnormal polymer, formed by combination of fibrin monomer and the 5.27S fibrinogen fragment, probably lack sufficient free linkage sites to permit normal polymerization. Support for this concept can be drawn from the work of Wallén and Bergström (33). The conversion by thrombin of a fibrinogen molecule to the reactive fibrin monomer form, capable of spontaneous polymer formation, involves the splitting off of fibrinopeptides A and B (14) (3 per cent of the total molecule nitrogen), a reaction presumably related to the unmasking of polymerization linkage sites. Wallén and Bergström ( 33 ) observed that when plasmin digests of fibrinogen were treated with thrombin the release of fibrinopeptides $A$ and $B$ was only half that of the original fibrinogen solution similarly treated, evidence compatible with the hypothesis that half the reactive sites involved in polymerization may have been destroyed by plasmin action.

The main significance of the present studies and those contained in the accompanying manuscripts $(1,32)$ resides in the demonstration that interference with the last stage of coagulationpolymer and gel formation from fibrin monomermay occur independently, or at least relatively independently, from other coagulation anomalies. However, if only conventional coagulation studies are performed and special methods designed to quantitate polymer gel formation rates are omitted, the coagulation defect may appear to be due to depletion of multiple specific coagulation factors. That defective fibrin polymerization is a biochemical lesion of considerable clinical significance is obvious from the present and accompanying (1) findings, but further investigation may well extend the scope and importance of this concept.

The demonstration that clot formation is not merely delayed but is also structurally defective carries important implications with regard to hemostatic and other clot functions, for these clots are mechanically fragile and have altered biochemical qualities. Indeed preliminary observations suggest that defective as apart from delayed clot formation involving altered polymer formation may be of significance in other coagulation disorders.

Moreover, these findings may have a wider biological implication than has been discussed in this communication. In vivo fibrin deposition is 
a homeostatic mechanism of wide general function, of which the securing of hemostasis is only a part. Consequently, it is conceivable, in view of the presence of proteolytic enzymes in tissues and in inflammatory exudates, that fibrin deposition because of the possibilities inherent in its structural alteration may possess functions of wider scope than has hitherto been appreciated.

\section{SUMMARY}

1. Patients suffering from pathological plasma proteolytic ("fibrinolytic") states develop, as a consequence of fibrinogen proteolysis, a coagulation defect dependent on the presence in plasma of fibrinogen proteolysis products. The two major coagulation anomalies observed are increase of the thrombin clotting time, and a macroscopically apparent defect in clot appearance and character.

2. The enzymatic actions of thrombin measured on the substrates BAMe and fibrinogen were not inhibited by the presence of fibrinogen proteolysis products; consequently, it would be inferred that fibrinogen proteolysis products inhibit the polymerization-gelation phase of coagulation. This inference was confirmed by the use of modified light-scattering procedures.

3. Fractionation of fibrinogen digests by several means revealed that a single large molecular weight fibrinogen fragment $\left(5.27 \mathrm{~s}_{20, w}\right)$, itself resistant to enzymatic digestion by plasmin or trypsin, was predominantly responsible for inhibition of fibrin polymerization.

4. Analysis of clots formed from plasma containing fibrinogen proteolysis products revealed that the large molecular weight fibrinogen fragment $\left(5.27 \mathrm{~s}_{20, \mathrm{w}}\right)$ was preferentially incorporated into clots and that the extent of such incorporation paralleled the severity of the coagulation defect. Consequently, the biochemical lesion responsible for the coagulation anomaly has been termed defective fibrin polymerization.

\section{ACKNOWLEDGMENTS}

It is a pleasure to record our indebtedness to Mrs. Odessa Turner and Mr. Arthur Sommer for technical assistance. The kindness of Dr. M. Seligmann of the Pasteur Institute, Paris, in supplying us with pre-publication copies of References 16-18 is gratefully acknowledged.

\section{REFERENCES}

1. Fletcher, A. P., Alkjaersig, X.. and Sherry, S. Pathogenesis of the coagulation defect developing during pathological plasma proteolytic ("fibrinolytic") states. I. The significance of fibrinogen proteolysis and circulating fibrinogen breakdown products. J. clin. Invest. 1962, 41, 896.

2. Sherry, S., Fletcher, A. P., and Alkjaersig, N. Fibrinolysis and fibrinolytic activity in man. Physiol. Rev. 1959, 39, 343.

3. Fletcher, A. P., Alkjaersig, N., and Sherry, S. The maintenance of a sustained thrombolytic state in man. I. Induction and effects. J. clin. Invest. 1959, 38, 1096.

4. Fletcher, A. P., Sherry, S., Alkjaersig, N., Smyrniotis, F. E., and Jick, S. The maintenance of a sustained thrombolytic state in man. II. Clinical observations on patients with myocardial infarction and other thromboembolic disorders. J. clin. Invest. 1959, 38, 1111.

5. Deutsch, E., and Fischer, M. Die Wirkung intravenös applizierter Streptokinase auf Fibrinolyse und Blutgerinnung. Thromb. Diath. haemor. 1960, 4, 482.

6. Johnson, A. J., and McCarty, WV. R. The lysis of artificially induced intravascular clots in man by intravenous infusions of streptokinase. J. clin. Invest. 1959, 38, 1627.

7. Blombäck, B. Studies on fibrinogen: Its purification and conversion into fibrin (Thesis). Acta physiol. scand. 1958, 43, suppl. 148.

8. Alkjaersig, N., Fletcher, A. P., and Sherry, S. The mechanism of clot dissolution by plasmin. J. clin. Invest. 1959, 38, 1086.

9. Ferry, J. D., and Morrison, P. R. Preparation and properties of serum and plasma proteins. VIII. The conversion of human fibrinogen to fibrin under various conditions. J. Amer. chem. Soc. 1947, 69, 388.

10. Alkjaersig, N., Fletcher, A. P., and Sherry, S. $\epsilon$-Aminocaproic acid: An inhibitor of plasminogen activation. J. biol. Chem. 1959, 234, 832.

11. Ehrenpreis, S., Laskowski, M., Jr., Donnelly, T. H., and Scheraga, H. A. Equilibria in the fibrinogenfibrin conversion. IV. Kinetics of the conversion of fibrinogen to fibrin monomer. J. Amer. chem. Soc. 1958, 80, 4255.

12. Ehrenpreis, S., and Scheraga, H. A. Kinetics of the conversion of fibrinogen to fibrin monomer at neutral pH. Arch. Biochem. 1959, 79, 27.

13. Biggs, R., and Macfarlane, R. G. Human Blood Coagulation and Its Disorders. Springfield, I1l., Charles C Thomas, 1957.

14. Scheraga, H. A., and Laskowski, M. The fibrinogen-fibrin conversion. Advanc. Protein Chem. 1957, XII, 1.

15. Scheraga, H. A., and Ehrenpreis, S. Kinetics of the fibrinogen-fibrin conversion in Proc. Fourth In- 
ternational Congress Biochemistry, E. Deutsch, Ed. New York, Pergamon Press, 1959, vol. X., p. 212.

16. Nussenzweig, V., and Seligmann, M. Analyse par des méthodes immunochimiques de la dégradation par la plasmine du fibrinogène humain et de la fibrine, a différents stades. Rev. Hémat. 1960, 15, 451.

17. Nussenzweig, V., Seligmann, M., Pelmont, J., and Grabar, P. Les produits de dégradation du fibrinogène humain par la plasmine. I. Séparation et propriétés physico-chimiques. Ann. Inst. Pasteur 1961, 100, 377.

18. Nussenzweig, V., Seligmann, M., and Grabar, P. Les produits de dégradation du fibrinogène humain par la plasmine. II. Etude immunologique: Mise en évidence d'anticorps anti-fibrinogène natif possédant des spécificités différentes. Ann. Inst. Pasteur 1961, 100, 490.

19. Seegers, W. H., Nieft, M. L., and Vandenbelt, J. M. Decomposition products of fibrinogen and fibrin. Arch. Biochem. 1945, 7, 15.

20. Mihályi, E. Electrophoretic investigation of fibrin and fibrinogen dissolved in urea solutions. Acta chem. scand. 1950, 4, 351.

21. Morrison, P. R. Preparation and properties of serum and plasma proteins: XV. Some factors influencing the quantitative determination of fibrinogen. J. Amer. chem. Soc. 1947, 69, 2723.

22. Niewiarowski, S., and Kowalski, E. Un nouvel anticoagulant dérivé du fibrinogène. Rev. Hémat. 1958, 13, 320.

23. Triantaphyllopoulos, D. C. Anticoagulant effect of incubated fibrinogen. Canad. J. Biochem. 1958, 36, 249.

24. Niewiarowski, S., Latallo, Z., and Stachurska, J. Apparition d'un inhibiteur de la thromboplastino- formation au cours de la protéolyse du fibrinogène. Rev. Hémat. 1959, 14, 118.

25. Triantaphyllopoulos, D. C. Nature of the thrombininhibitory effect of incubated fibrinogen. Amer. J. Physiol. 1959, 197, 575.

26. Niewiarowski, S., Latallo, Z., and Stachurska, J. Un nouvel inhibiteur de la génération de thromboplastine-I. G. T-produit au cours de la dégradation protéolytique du fibrinogène. Sang 1959, 30, 376.

27. Triantaphyllopoulos, D. C. Effects of intravenous injections of the anticoagulant fraction of incubated fibrinogen on blood coagulation. Canad. J. Biochem. 1960, 38, 909.

28. Kopeć, M., Kowalski, E., and Stachurska, J. Studies on paracoagulation. Role of antithrombin VI. Thromb. Diath. haemor. 1960, 5, 285.

29. Triantaphyllopoulos, D. C. Anticoagulant action of TAMe and AFIF. Amer. J. Physiol. 1961, 200, 771.

30. Latallo, Z. S., Fletcher, A. P., Alkjaersig, N., and Sherry, S. Influence of $\mathrm{pH}$, ionic strength, neutral ions and thrombin on fibrin polymerization. Amer. J. Physiol. In press.

31. Latallo, Z. S., Fletcher, A. P., Alkjaersig, N., and Sherry, S. Inhibition of fibrin polymerization by fibrinogen proteolysis products. Amer. J. Physiol. In press.

32. Bang, N. U., Fletcher, A. P., Alkjaersig, N., and Sherry, S. Pathogenesis of the coagulation defect developing during pathological plasma proteolytic ("fibrinolytic") states. III. Demonstration of abnormal clot structure by electron microscopy. J. clin. Invest. 1962, 41, 935.

33. Wallén, $P$., and Bergström, $K$. Action of thrombin on plasmin digested fibrinogen. Acta chem. scand. 1958, $12,574$. 